\title{
Propostas curriculares alternativas: Limites e avanços
}

\author{
Antonio Flavio Barbosa Moreira*
}

\begin{abstract}
RESUMO: O texto aborda propostas curriculares que procuraram caminhar na contramão do discurso oficial hegemônico e que foram desenvolvidas, nas décadas de 1980 e 1990, em alguns estados e municípios brasileiros. Caracterizaas, destaca suas conquistas e enfatiza que alternativas são possíveis, desejáveis e merecedoras de divulgação e de estudo.
\end{abstract}

Palavras-chave: Proposta curricular, alternativa, democratização, integração curricular, currículo centrado na escola

\section{Introdução}

Em numerosos estudos, têm-se criticado as recentes reformas educativas promovidas em grande parte do mundo, nas quais assumem relevo os esforços por reformular os currículos dos distintos graus de ensino. Utilizando variados referenciais teóricos, as análises alertam, dentre outros aspectos, para o fato de que as propostas se inserem em um movimento universal destinado a reestruturar os sistemas educativos das sociedades ocidentais do bem-estar (Carlgren 1998), desempenham importante papel nos processos de legitimação que ocorrem nessas sociedades (Popkewitz, Pitman e Barry 1998), expressam os interesses conservadores de grupos de direita que procuram aplicar às escolas as leis do livre mercado (Apple

Professor titular da Faculdade de Educação da Universidade Federal do Rio de Janeiro.E-mail: afmcju@infolink.com.br. 
1993; Whitty, Power e Halpin 1998) e se concretizam em práticas globais cujas implicações são produzir sistemas de inclusão e de exclusão (Burbules 1998). Acentuam, também, que as mudanças curriculares costumam ser acompanhadas de tentativas de implantação de um sistema nacional de avaliação e de alteração dos arranjos pelos quais se formam e se aperfeiçoam os docentes (Apple 1994; Goodson 1994, Moreira 1995).

Dominantemente, têm sido estudadas as reformulações curriculares oficiais que se realizam segundo a ótica neoliberal. As que procuram caminhar em direção contrária ao discurso hegemônico ainda têm sido pouco focalizadas, ao menos no Brasil. Em outro estudo (Moreira 1998), argumento que análises dessas propostas alternativas, que a meu ver se fazem bastante necessárias, podem contribuir tanto para o avanço do conhecimento no campo do currículo como para estimular outras reações. A intenção não é a busca da alternativa, mas a divulgação de alternativas que se fazem viáveis em determinados espaços e em determinados momentos históricos, para que se promovam inteligibilidades e cumplicidades recíprocas (Souza Santos 2000).

Dentre os autores que acreditam na possibilidade de resistências à visão conservadora de educação que crescentemente se difunde pelo mundo, pode-se mencionar, nos Estados Unidos, Apple e Beane (2000). Em recente coletânea, os autores focalizam práticas criativas desenvolvidas em quatro escolas norte-americanas por educadores, pais, membros da comunidade e estudantes, em resposta às pressões feitas para que as instituições escolares atendessem às exigências do mercado. Convictos de que outras experiências podem ser realizadas e de que, em muitos países, educadores críticos procuram formas de enfrentar as dificuldades e materializar suas convicções democráticas, os autores defendem a criação e a expansão de espaços em que se contem as histórias de práticas inovadoras bem-sucedidas.

Concordando com Apple e Beane, coloco-me em posição oposta às análises que enfatizam o rompimento das fronteiras entre o oficial $\mathrm{e}$ o alternativo e destacam as similaridades entre propostas oficiais e propostas alternativas (que se evidenciariam, por exemplo, na utilização das mesmas palavras - cidadania, democracia, participação, qualidade). Essa perspectiva, a meu ver, secundariza as expressivas diferenças envolvidas nas condições de produção dos dois discursos e nos fins sociais e políticos que os norteiam. 
Ciente de que palavras associadas às lutas progressistas têm sido assimiladas e recontextualizadas por setores mais conservadores, o que exige cuidado e rigor no emprego de determinados termos, reafirmo as diferenças entre os dois tipos de discursos. Por distingui-los e por julgar que é possível e desejável aprender com os avanços e as dificuldades envolvidas na concretização de práticas e de políticas curriculares alternativas, proponho-me, neste estudo, a rever as propostas que se elaboraram nos anos 80 e 90 em alguns estados e municípios. Pretendo, com essa revisão, tanto realçar preocupações e medidas que, a meu ver, constituem conquistas das reformulações em pauta, como refletir sobre desafios a serem enfrentados. Acompanha-me, então, o ponto de vista de que alternativas ao existente são possíveis, desejáveis e merecedoras de estudo e divulgação.

\section{As propostas alternativas dos anos 80: a democratização do espaço escolar}

O movimento de renovação curricular dos anos 80 ocorreu predominantemente nas regiões Sudeste e Sul, a partir das eleições de governos de oposição ao regime militar. A intenção prioritária era melhorar a qualidade do ensino oferecido na escola pública e reduzir as altas taxas de repetência e evasão escolar que penalizavam, dominantemente, as crianças das camadas populares. Procurava-se, também, incentivar a participação da comunidade escolar nas decisões, de forma a superar-se o autoritarismo de reformas anteriores, com freqüência impostas de "cima para baixo".

No que se refere especificamente às mudanças curriculares propostas, tenderam a ampará-las a pedagogia crítico-social dos conteúdos e a educação popular, duas tendências pedagógicas de significativa importância na configuração do campo do currículo na década em questão. Ainda que concordando com a necessidade de se teorizar a partir da situação específica da realidade educacional brasileira, bem como com a urgência de se construir uma escola de qualidade para os alunos das classes populares, as duas tendências divergiam radicalmente em relação ao conteúdo a ser ensinado nessa escola.

Considerando que caberia ao Estado determinar uma base comum de conhecimentos que organizasse o sistema de ensino e favorecesse a unificação nacional e o desenvolvimento cultural da sociedade, a peda- 
gogia dos conteúdos colocava-se a favor de programas oficiais a serem desdobrados pelos professores, consideradas as condições da escola, as experiências dos alunos, bem como as situações didáticas específicas às diferentes séries e matérias. Ao buscar resgatar a importância dos conteúdos e ao ressaltar a função básica da escola - a transmissão do saber sistematizado-, defendia a existência de um conhecimento científico, universal e objetivo, a ser dominado por todos os estudantes. Embora produzido historicamente, no interior das relações sociais, tal conhecimento, ao expressar as leis que regem os fenômenos naturais e sociais, era visto como transcendendo os interesses individuais, origem de classe e restrições históricas. De seu tratamento deviam derivar os conteúdos escolares, a serem criticamente ensinados a todos os estudantes, principalmente aos oriundos das camadas populares, para os quais a escola constituía o espaço em que essa aquisição poderia de fato ocorrer (Libâneo 1990; Saviani 1983). Daí a afirmativa de Mello (1986): "que os professores ensinem e os alunos aprendam (o quê, senão esse saber historicamente disponível?)" (p. 52).

Nessa perspectiva, aceitavam-se sem questionamento tanto a organização disciplinar como as próprias disciplinas escolares tradicionais.

Todos vamos ter que falar a mesma língua, o raciocínio lógico matemático e as estruturas mentais do povo brasileiro devem ser desenvolvidos, todo mundo precisa conhecer a história e a geografia do país. (Mello 1986, p. 176)

Não foi, então, na proposição de novas grades curriculares ou no esforço por integrar conteúdos de diferentes disciplinas que se concentraram as preocupações das reformulações curriculares pautadas na pedagogia dos conteúdos, como as realizadas em Minas Gerais e São Paulo, empenhadas, fundamentalmente, em oferecer aos alunos das camadas populares um bom ensino e em democratizar o espaço escolar.

No estado de Minas Gerais, o processo é liderado por Neidson Rodrigues, ${ }^{1}$ que conclamou professores, alunos e pais à participação nas mudanças pretendidas. A fim de realizar um diagnóstico da situação das escolas, conhecer os projetos pedagógicos em desenvolvimento e sistematizar as propostas para uma nova política de educação, a Secretaria de Educação, com o apoio de inúmeras outras entidades ligadas à educação, organizou o Congresso Mineiro, no qual estiveram presentes mais 
de 5 mil escolas estaduais. Ainda que a participação não tenha sido a esperada, pode-se assinalar como principal contribuição do Congresso o abandono, no âmbito da Secretaria, de métodos autoritários no tratamento de questões educacionais.

Em termos pedagógicos, adotou-se o ponto de vista de que a escola deveria transmitir a todos os que a ela tivessem acesso, sem discriminação, "o saber universal, ou seja, o saber historicamente acumulado, necessário à formação dos cidadãos" (Estado de Minas Gerais, citado por Cunha 1991). Assim, com o apoio dos atores mais envolvidos na escola, procurouse destacar sua especificidade, entendida em consonância com os princípios defendidos pela pedagogia dos conteúdos. A proposta curricular do Plano Mineiro preservou as disciplinas tradicionais, enfatizando, ao mesmo tempo, a necessidade de renovações no ensino, particularmente nas disciplinas ciências, história, geografia e educação para o trabalho. Desejava-se direcioná-las, respectivamente, para os seguintes objetivos: o domínio da linguagem científica, a compreensão da realidade cultural como produto histórico das ações humanas, a compreensão do espaço como realidade viva, a compreensão das condições da vida do homem e da sociedade em suas determinações fundamentais e representações culturais. Muito claramente, a escola unitária de Gramsci e a pedagogia dos conteúdos inspiraram a busca de solução dos problemas que dificultavam o cumprimento da função social da escola pública (Cunha 1991).

No município de São Paulo, Guiomar Namo de Mello ${ }^{2}$ coordenou a reformulação implementada. Nela também se valorizou a escola como transmissora do saber sistematizado, de validade universal, que constituía parte dos bens culturais produzidos historicamente pela humanidade. A mudança curricular prevista não chegou a ser integralmente concretizada, mas se extinguiu a disciplina estudos sociais na $5^{\mathrm{a}}$ e $6^{\mathrm{a}}$ séries, voltandose a ensinar as tradicionais história e geografia. Em documento oficial, registrou-se a intenção de desenvolver trabalho educativo capaz de atender às "necessidades de aprendizagem e às características sociopsicoculturais das crianças das camadas populares, permitindo que 0 aluno adquira e domine efetivamente as habilidades e os conceitos básicos das diferentes áreas do conhecimento" (Município de São Paulo, citado por Cunha 1991). A organização disciplinar foi mantida, em sintonia com a pedagogia dos conteúdos, cuja influência foi, mais uma vez, óbvia. Priorizou-se a seqüência lógica dos conteúdos de cada disciplina, de modo a ressaltar o que fosse essencial. 
Elaborou-se novo regimento para as escolas municipais, no qual se procurava redistribuir o poder, particularmente pela ação do Conselho da Escola, cujas funções passaram de consultivas para deliberativas e cujas reuniões ocorreriam bimensalmente. O Conselho era formado por professores, pais, alunos, administradores e funcionários, garantindo-se a paridade entre o número de representantes dos pais e o número de representantes de docentes (Cunha 1991).

O regimento representou, em São Paulo, instrumento central no processo de democratização da escola, visto por Mello (1986) como envolvendo fatores externos e internos. Externamente, a democratização incluiria o acesso e a permanência de todas as crianças na escola de oito anos, a oferta de melhor qualidade de ensino possível ao maior número possível de alunos, assim como a abertura da escola para a participação da população usuária. A democratização interna, componente indispensável da construção da externa, envolveria a democratização das relações internas entre educadores, educandos e familiares.

A reforma curricular implementada no Estado do Rio de Janeiro ${ }^{3}$ apresentou características bem distintas das de Minas e São Paulo. Verificou-se, dentre outras, a influência dos pressupostos da educação popular, cujos autores se inspiravam em Paulo Freire e defendiam a utilização, na escola, dos fundamentos que norteassem o ensino desenvolvido em outros espaços, para e por comunidades específicas. Valorizavam o saber popular, dele buscavam partir e o empregavam no processo de conscientização das camadas subalternas. Apesar disso, rejeitavam a dicotomização entre transmissão do saber sistematizado e conscientização (Giroux 1986), argumentando que tudo o que fosse ensinado e aprendido deveria sê-lo criticamente.

Os currículos pautados nos princípios de Freire deveriam ter como eixo organizador as necessidades e as exigências da vida social, não as disciplinas tradicionais. Daí a preocupação em codificar e decodificar temas geradores, trabalhados nas salas de aula por meio do diálogo entre professores e estudantes. É, aliás, pelo diálogo com outros educadores e intelectuais que se elaboraram muitos dos últimos livros de Freire. Em um deles, com Ira Shor, os dois interlocutores acentuaram que um currículo oficial comum representa uma forma autoritária e mecânica de organizar o ensino, que expressa desconfiança em relação à habilidade dos estudantes e à competência dos professores, assim como constitui 
uma tentativa de manipulação de suas atividades. Adotando outra perspectiva, sugeriram que se organizasse o currículo criativamente, a partir de uma pedagogia que, considerando os temas, as necessidades e a linguagem dos alunos, reinventasse o conhecimento e o utilizasse no desvelamento das relações de poder na sociedade. Daí a preferência dos autores associados à educação popular por currículos mais localmente definidos, ao invés de currículos decididos, em instâncias centrais, para todo um sistema escolar (Freire e Shor 1987).

Na reformulação realizada no Rio de Janeiro, muitos desses princípios não foram seguidos. As disciplinas e os métodos de ensino tradicionais foram basicamente preservados e associados a diferentes atividades culturais, pautadas pelo respeito à cultura popular. Foi nesse sentido que mais se fez presente a influência de Freire. Particularmente nas escolas de tempo integral, cuja implantação foi liderada por Darcy Ribeiro, a proposta pedagógica combinou diferentes tendências, misturando elementos da educação popular, da pedagogia dos conteúdos e mesmo do escolanovismo com Piaget, Rogers e Gramsci. Elementos de teorizações críticas integraram-se, assim, a princípios psicológicos referentes ao desenvolvimento e à aprendizagem. O propósito foi associar aquisição de conteúdos e conscientização, de acordo com as sugestões dos adeptos da educação popular.

A partir da preocupação em oferecer às crianças das camadas populares condições de aprendizagem, de enriquecimento cultural e de engajamento na luta por mudança social, estabeleceram-se, no estado do Rio de Janeiro, como prioridades para a esfera educacional, o aumento da permanência do aluno na escola, com a eliminação do chamado terceiro turno, e a ampliação da rede escolar, com a construção de escolas de tempo integral. Insistindo-se no respeito aos saberes da criança pobre, sustentou-se que a escola deveria servir de ponte entre o conhecimento prático já adquirido e o conhecimento formal exigido pela sociedade letrada.

Também se pretendeu, no Rio de Janeiro, democratizar o processo decisório. No segundo semestre de 1983, Darcy Ribeiro presidiu a Comissão Coordenadora de Educação e Cultura, promovendo o I Encontro de Professores de Primeiro Grau, no qual se discutiram teses distribuídas em três grupos: problemas da escola pública, metas da ação do governo em educação e participação dos professores nessa programação. Reunidos os professores em cerca de 500 locais, em 11 de novembro de 1983, buscou-se organizar, com as bases, o programa de educação do estado. 
Cerca de 50 mil professores participaram do encontro e escolheram representantes para a elaboração e a apresentação de relatórios em nova fase, realizada em 26 e 27 de novembro em Mendes. Conforme Cunha (1991), os relatórios nem sempre foram convergentes ou compatíveis com os planos de fato já elaborados. As teses foram vistas como impostas e duramente criticadas. Os docentes propuseram o Centro Estadual de Professores (CEP) como interlocutor junto ao governo e recusaram algumas das propostas apresentadas. O conflito foi inevitável e o encontro terminou desastrosamente, sem que se conseguisse criar um espaço mais democrático de tomada de decisões.

Por dedicar-se intensamente à implantação dos Centros Integrados de Educação Pública (CIEPs), o governo acabou relegando a rede escolar existente ao abandono. Em pouco tempo deixou definitivamente de contar com o apoio e a participação dos professores, acusados, então, de elitismo. Usados abusivamente como propaganda política do governo, os CIEPs foram fortemente criticados, denunciando-se sua dimensão assistencialista, bem como as dificuldades envolvidas em implementá-los com os professores trabalhando em tempo parcial (Cunha 1991).

O breve exame das três reformulações permite algumas considerações. Em decorrência dos estímulos das administrações em pauta e/ou da mobilização do professorado, em consonância com a organização da sociedade civil na década de 1980 , criaram-se alguns espaços para novas relações entre escola e secretaria, entre os diversos sujeitos da escola, bem como entre escola e comunidade. Pode-se considerar que a tentativa de democratizar a escola reforçou a luta pela redemocratização da sociedade, consolidando a idéia de que a própria educação correspondia a um direito de cidadania e deveria instrumentalizar os estudantes para uma participação mais ativa nos assuntos relativos aos interesses comuns (Barreto 1998). O esforço por instituir a democracia na escola contribuiu para reverter, ao menos parcialmente, o autoritarismo das reformas oficiais da ditadura, conduzidas por "comissões de notáveis" que, sem a participação dos sujeitos diretamente interessados, elaboravam "pacotes" dificilmente "digeríveis" nas escolas. A organização do currículo e a gestão da escola modificaram-se e passaram a envolver, de diferentes formas e em diferentes graus, professores, alunos e membros da comunidade. Lamentavelmente, postulações partidárias, nem sempre congruentes com os interesses populares, reduziram a participação dos interessados no debate sobre as questões de currículo, reafirmando, então, as vozes dos 
profissionais do ensino e dos especialistas (Barreto 1998). De qualquer modo, disseminaram-se, nas escolas, práticas mais democráticas, avançando-se consideravelmente em relação ao panorama antes vigente.

O discurso teórico adotado nas reformas pretendeu constituir referência para a seleção de conteúdos significativos no interior das disciplinas. No entanto, o posicionamento a favor das classes populares nem sempre foi capaz de subsidiar o tratamento a ser dado a cada disciplina. O discurso, com conotação fortemente política, chocava-se freqüentemente com as proposições dos especialistas nas disciplinas que, efetivamente, acabaram afetando sobremaneira o tom dos guias curriculares.

O flagrante descompasso entre os objetivos enunciados e o que é proposto para alcançá-los talvez se deva ao fato de que a revisão dos conteúdos curriculares em função de uma nova ótica dependa em grande medida, nesse desenho de currículo, do nível de elaboração dessas questões no âmbito das respectivas áreas de conhecimento. (Barreto 1995)

Registre-se a ausência, na fundamentação teórica das propostas, dos princípios da sociologia do currículo, que já se difundia no país ao final da primeira metade da década. A pedagogia dos conteúdos e/ou a educação popular mostraram-se as interlocuções preferidas, vistas, portanto, como capazes de oferecer melhores respostas aos problemas enfrentados.

Os resultados das reformas ficaram aquém dos esperados. Segundo algumas análises, a idéia de que das consultas, das decisões comuns, emergiriam as soluções para as deficiências da escola refletiu uma perspectiva por demais entusiasta e ingênua. A maior participação não garantiu, necessariamente, a execução das medidas indispensáveis à transformação desejada (Teixeira 1999). Como as mudanças implementadas não afetaram de modo significativo as questões estruturais dos sistemas públicos, em grande parte responsáveis pelo fracasso escolar, chegou-se aos anos 90 sem que os índices de evasão e repetência se alterassem mais incisivamente (Barreto 1998), mas com conquistas que precisam ser reconhecidas. Destaco, dentre elas, o empenho em democratizar a escola e a valorização dos conteúdos curriculares, desprestigiados, em momentos anteriores, pelo realce dado a métodos, técnicas e experiências de aprendizagem. 
As propostas alternativas dos anos 90: 0 desenvolvimento de currículos centrados nas escolas

As novas tendências que conformaram o campo do currículo nos anos 90 não parecem ter subsidiado significativamente as reformulações curriculares na década. Influenciados pelos estudos culturais, pelo pósmodernismo e pelo pós-estruturalismo, os textos preservaram a preocupação com o conhecimento escolar, abordando ainda temas como: o nexo poder-saber no currículo, a transversalidade no currículo, novas organizações curriculares, as interações no currículo em ação, o conhecimento e o cotidiano escolar como redes, o currículo como espaço de construção de identidades, o currículo como prática de significação, a expressão das dinâmicas sociais de gênero, sexualidade e etnia no currículo, o multiculturalismo.

Toda essa efervescência, segundo algumas análises, não se revelou suficiente para a superação do distanciamento entre a produção 'teórica' e a realidade vivida no cotidiano das escolas (Souza 1993), bem como para a formulação de currículos em sintonia com as especificidades do contexto brasileiro. Em outras palavras, o que se sugere é que o discurso elaborado no Brasil, nos anos 90, por seu caráter complexo e abstrato e pela escassez de proposições que oferece para os profissionais da educação, não chegou ainda a nortear novas práticas e reformas.

A penetração do que vem sendo chamado de teorização pós-crítica nas propostas curriculares dos anos 90 limitou-se a algumas sugestões sobre multiculturalismo, gênero e sexualidade. Para os setores mais conservadores, trata-se de temas, de valores e de princípios "perigosos". Os setores de esquerda, por outro lado, mais preocupados com desigualdades sociais e econômicas do que com diferenças decorrentes de outros fatores, ainda hesitam em assimilar as novas idéias. Desse modo, tem sido na pedagogia crítica, principalmente na de Paulo Freire, que tais setores têm encontrado mais afinidades ideológicas e mais sugestões para a prática.

A influência da pedagogia crítica expressou-se, na década em tela, em reformas curriculares que se propuseram a desafiar o caráter centralizador das propostas do MEC e que se realizaram principalmente em estados e municípios em que a oposição conseguiu eleger seus governantes. Apesar dos esforços do governo federal em difundir seus Parâ- 
metros Curriculares Nacionais (PCN) para todo o país, outras propostas, desenvolvidas com razoável grau de autonomia, destacaram-se, ampliando as iniciativas e os avanços da década anterior. Refiro-me particularmente às reformas nos municípios de São Paulo (1989-1992), Rio de Janeiro (1993-1996 e 1997-2000), Belo Horizonte (1993-1996) e Porto Alegre (1994 em diante).

O caráter diverso e plural de nossas grandes cidades parece ter favorecido os ensaios nas redes públicas municipais, em que se organizaram currículos a partir de princípios mais integradores, visando a propiciar aos grupos subalternizados da população uma aprendizagem mais significativa e mais bem-sucedida. As propostas pautaram-se na "idéia de integração do currículo como recurso facilitador da postura reflexiva em relação ao saber constituído, reiterando o propósito de inserção do aluno na sociedade como cidadão autônomo, consciente e crítico" (Barreto 1998, p. 27). No entanto, não ignoraram (nem poderiam) as determinações legais que prescrevem as disciplinas a serem ensinadas na escola.

Nas quatro capitais, os princípios para a ordenação ou integração do currículo diferiram. Em São Paulo e Porto Alegre escolheu-se a interdisciplinaridade; em Belo Horizonte, preferiram-se eixos transversais e norteadores; no Rio de Janeiro, os princípios educativos e núcleos conceituais. Escapou-se, assim, da idéia de que uma proposta curricular corresponde a uma lista detalhada de conteúdos, procedimentos e avaliação para todas as escolas. Entendeu-se que essa definição deve ocorrer no âmbito do projeto pedagógico de cada escola, cabendo aos órgãos centrais o estabelecimento dos objetivos gerais norteadores dos projetos. Como se vê, o foco foi mais na integração de conhecimentos localmente escolhidos que no saber sistematizado universal, defendido pela pedagogia dos conteúdos. Não surpreende, então, a significativa influência de Freire em quase todas as reformulações.

No município de São Paulo, ${ }^{5}$ a proposta político-pedagógica foi orientada por três princípios: participação, descentralização e autonomia. O quadro de referência teórico-metodológico privilegiou: a valorização da relação teoria-prática; o princípio da interdisciplinaridade; a relação dialógica; o desenvolvimento dos programas das escolas a partir do estudo da realidade local (Arelaro 1999). Nesse sentido, elaboraram-se estudos da comunidade para verificar os problemas vivenciados pela população. Organizou-se o material coletado, discutiram-se as informações em grupo 
com vistas à construção de categorias, definiram-se categorias para identificação e análise das situações mais significativas da comunidade (São Paulo, Secretaria Municipal de Educação de São Paulo 1990a). Selecionaram-se os temas geradores, vistos como caminhos para se conhecer, compreender e intervir criticamente na realidade. Tais temas pressupunham uma metodologia de trabalho coletivo pautado no diálogo e constituíam pontos de encontro interdisciplinares das áreas de saber (São Paulo, Secretaria Municipal de Educação de São Paulo 1991). As disciplinas foram chamadas a interpretá-los: os conteúdos eram selecionados e "construídos" pelo educador com base em suas contribuições para o estudo dos temas. A interdisciplinaridade se fez, assim, mais no plano da prática pedagógica e nas questões sociais que no plano epistemológico propriamente dito. A especificidade de cada área do conhecimento foi mantida, mesmo quando se pretendia relativizar a dicotomia entre o saber escolar e o do senso comum e abrir caminhos para o enriquecimento recíproco.

Nesse enfoque, concebeu-se o currículo como o instrumento básico da ação transformadora escolar, como extrapolando listagens de disciplinas e atividades, para englobar ações e relações, de fora para dentro e de dentro para fora, propostas e existentes, na escola, pela escola e para a escola (São Paulo, Secretaria Municipal de Educação 1990a). O currículo foi visto como uma construção coletiva, como um processo, requerendo uma estrutura escolar mais flexível, democrática e autônoma. A organização do ensino em ciclos impõe-se, então, como necessária a uma escola que se queria menos seletiva, menos excludente e menos autoritária (Arelaro 1999).

Nas bibliografias de documentos elaboradas pela Secretaria Municipal de Educação de São Paulo (São Paulo, Secretaria Municipal de Educação 1989a, 1989b, 1990a, 1990b, 1991) pode-se constatar a esperada e forte presença de Paulo Freire, bem como de autores de psicologia, de interdisciplinaridade, de avaliação e de currículo. O diálogo com teóricos do campo do currículo, tanto nacionais como internacionais, ainda que menos intenso do que com outros especialistas, esboça-se nas discussões sobre: seleção e organização do conhecimento escolar; paradigmas curriculares; reprodução e resistência na escola; currículo oculto; relações entre currículo, ideologia e poder.

No município de Porto Alegre, ${ }^{6}$ a proposta da Escola Cidadã assumiu contornos semelhantes, dispondo-se a redimensionar as relações 
de poder, a organização administrativa, os tempos, os espaços e o currículo (Gorodicht e Souza 1999). O ensino fundamental se organizou em ciclos de formação ( 3 ciclos de 3 anos cada), de modo a garantir o respeito ao ritmo, ao tempo e às experiências de cada educando, assim como às possibilidades de organização coletiva e interdisciplinar da escola. Os ciclos foram vistos como capazes de flexibilizar a seriação e permitir um reagrupamento dos alunos em função de interesses comuns e da adequação idade/escolaridade (Azevedo 1999; Frigotto 1999).

Três eixos nortearam a proposta: a interdisciplinaridade, a avaliação emancipatória e a educação popular. Organizou-se o desenho curricular a partir de complexos temáticos, elaborados, em princípio, no início de cada ciclo de formação ou de cada ano do ciclo. O complexo temático foi definido como

um processo que proporciona o conhecimento, a investigação e a reflexão da realidade, da forma implícita de pensar e de agir das pessoas que com ela e nela interagem para, num movimento dialógico coletivo de negociações, estruturar-se uma ação educacional possível. (Gorodicht e Souza 1999, p. 77)

A proposta apontou também para estudos da comunidade, por meio de pesquisas socioantropológicas desenvolvidas pelos professores, com resultados discutidos pela equipe docente para definir o eixo do trabalho pedagógico e os conceitos das diferentes áreas e disciplinas. O conhecimento expresso no complexo temático deveria incluir o conhecimento científico e o do cotidiano, sem hierarquizações, mas em permanente confronto, com vistas ao questionamento e ao desvelamento do senso comum e das ideologias subjacentes aos saberes. Nesse processo, a idéia era partir do universo cultural dos alunos em direção a um conhecimento mais universal (Frigotto 1999).

Marca distintiva da pedagogia desenvolvida em Porto Alegre, o trabalho com temas geradores ou complexos temáticos tem sido alvo de críticas e de avaliações positivas. Para alguns críticos, os temas de conotação social, por se pautarem no que Paulo Freire preconiza para programas de educação de adultos, terminam por não considerar devidamente as especificidades dos interesses infantis e as diferenças entre as faixas etárias. Segundo Barreto (1998), em cursos de longa duração, o emprego do mesmo tema torna tênue o fio condutor que deve assegurar 
a progressão e a abordagem dos conteúdos. A conseqüência pode ser tanto o recurso à seqüência tradicional de conteúdos, como a falta de sistematização e a superficialidade no seu tratamento. Para outros críticos, a utilização das disciplinas tradicionais no estudo dos temas geradores, com seus territórios ainda delineados, mantém a fragmentação que se pretendia evitar.

Por outro lado, os temas geradores ou complexos temáticos são elogiados devido aos efeitos positivos que costumam produzir. Ao elaborar seu planejamento a partir dos problemas selecionados, cada professor precisa definir e justificar a importância de certos conteúdos de suas disciplinas. Constata-se que o desempenho dessa tarefa tende a convencê-lo da necessidade de um processo permanente de atualização (Frigotto 1999).

Como em São Paulo, a formação continuada de professores tem constituído especial objeto de atenção da Secretaria de Educação de Porto Alegre, que a ela se vem dedicando de modo intenso e peculiar, promovendo seminários internacionais, seminários nacionais, encontros e cursos para o professorado. ${ }^{7}$ O sucesso da Escola Cidadã, ainda hoje em desenvolvimento, precisa ser creditado à continuidade na administração da cidade de Porto Alegre e na Secretaria de Educação. Iniciado em 1994, o projeto tende a continuar, se forem confirmadas as previsões de nova vitória do PT nas eleições municipais de 2000, para o período 2001-2004. ${ }^{8}$

Os autores da Escola Plural, ${ }^{9}$ de Belo Horizonte, não aceitaram a concepção de interdisciplinaridade adotada em São Paulo e em Porto Alegre. Argumentaram que, embora ela assegurasse o interesse e o trabalho conjunto dos professores, não contemplava devidamente o aluno como elemento ativo no processo de produção do conhecimento. Propuseram, então, um desenho curricular inspirado no currículo espanhol em vigência e sugeriram a inserção de temas contemporâneos de apelo social, que ultrapassassem os campos específicos das diferentes áreas do conhecimento escolar. Os temas funcionariam como eixos transversais, perpassando as diferentes disciplinas e dotando-as de valor social. A educação para a cidadania constituiu tema transversal nuclear, secundada por temas como meio ambiente, diversidade cultural, gênero, etnia, sexualidade e consumo.

O cruzamento de temas e disciplinas foi considerado o suporte a partir do qual se construiriam o projeto curricular e a programação de conteúdos coerentes e significativos. 
Nessa perspectiva, o processo de ensino/aprendizagem não tem como finalidade a transmissão de conteúdos prontos, mas, sim, a formação de sujeitos capazes de construir, de forma autônoma, seus sistemas de valores e, a partir deles, atuarem criticamente na realidade que os cerca. (Belo Horizonte, Secretaria Municipal de Educação 1994, p. 33)

A proposta da Escola Plural também não derrubou as barreiras entre as disciplinas. Os temas transversais, aplicados como elementos integradores, do mesmo modo que nos PCNs, constituem elementos além das disciplinas, que as atravessam, complementam e preservam. A fragmentação tende, assim, a continuar. Para de fato romper-se a compartimentação no currículo, tudo precisaria tornar-se tema transversal - temas e problemas deveriam ser tratados transversalmente. $O$ eixo vertebrador do currículo seria constituído, então, por saberes transversais que, atravessando diferentes campos do conhecimento, não se identificariam com apenas um deles. Esse enfoque, experimentado apenas em cursos superiores, permitiria a superação das disciplinas (Alves e Garcia 1999; Zaccur e Garcia 1996).

No Rio de Janeiro, na proposta Multieducação (1993/1996), ${ }^{10}$ considerou-se a escola como ambiente privilegiado para a construção sistemática de conhecimentos e a aquisição de valores. Procurou-se relacionar as vivências cotidianas e o saber escolar com base na intersecção de princípios educativos, de forte acento social, com núcleos conceituais, de natureza epistemológica. A intenção era a construção de um sujeito ético, autônomo, solidário, crítico e transformador.

Constituíram princípios educativos: meio ambiente, trabalho, cultura e linguagem. Os núcleos conceituais corresponderam aos elementos estruturantes do conhecimento que atravessam as diferentes áreas e disciplinas. Propuseram-se quatro núcleos: identidade, tempo, espaço e transformação. Cada professor e cada equipe escolar deveriam repensar e replanejar suas ações a partir da articulação de princípios e núcleos, visando a uma sociedade mais justa e democrática, meta para a qual a ação escolar foi vista como capaz de contribuir (Rio de Janeiro, Secretaria Municipal de Educação do Rio de Janeiro 1996).

O processo de combinação de princípios educativos e núcleos conceituais objetivou também a construção de critérios para a seleção e a ordenação dos conteúdos referentes aos componentes curriculares e 
à formação de atitudes (Barreto 1998). Desejava-se possibilitar ao aluno não apenas compreender, mas incorporar o conhecimento sob a forma de esquemas operatórios.

\begin{abstract}
A hipótese é que os conceitos nucleares teriam uma dupla natureza - transdisciplinar e transcultural -, o que garantiria à construção de um núcleo curricular básico uma base relacional, quer no eixo cultural, quer no eixo disciplinar. (Bonamino e Brandão, citados por Barreto 1998, p. 33)
\end{abstract}

Observando-se a bibliografia da proposta, verifica-se a presença, dentre outros, de Paulo Freire, de autores de psicologia, de avaliação e de interdisciplinaridade (Rio de Janeiro, Secretaria Municipal de Educação do Rio de Janeiro 1996). A produção específica de currículo, todavia, encontra-se muito pouco representada.

Julgo que a proposta do Rio de Janeiro é passível de críticas tanto por sua complexidade, o que a torna pouco acessível ao professorado, como por exigir, em sua implementação, recursos, condições de trabalho e de apoio à prática desenvolvida que se têm mostrado pouco disponíveis em uma rede de mais de mil escolas. Pode também ser criticada por não superar a compartimentação dos saberes expressa nas disciplinas, ainda que incentive a "que se tente 'saltar as cercas entre as disciplinas'" (Rio de Janeiro, Secretaria Municipal de Educação do Rio de Janeiro 1996, p. 388).

Pode-se verificar que todas as quatro experiências deslocaram o processo de construção curricular dos órgãos centrais das redes de ensino para o âmbito da escola. Adotaram um conjunto de princípios gerais, a partir dos quais docentes, estudantes e pais passaram a elaborar o currículo em cada escola. Os professores deixaram de ser meros executores de prescrições centralmente elaboradas, tornando-se o processo mais democrático e garantindo-se espaço para a diversidade no currículo. A comunidade foi estimulada a participar, a estar presente nas decisões coletivas, de modo a envolver-se afetivamente com as atividades escolares. Todas as propostas caminharam, assim, em oposição às tentativas centralizadoras do governo federal, apresentando como principais conquistas os esforços por democratizar o espaço escolar, por desenvolver currículos centrados nas escolas e por promover a integração dos conteúdos e das atividades.

Desse modo, a intenção de homogeneizar o que se ensina nas escolas, com vistas a oferecer suporte a um sistema nacional de avaliação 
que se vem implantando aos poucos no país, tem sido desafiada pela liberdade de que desfrutam estados e municípios em uma república federativa, liberdade explorada ao máximo por governadores, prefeitos e secretários de educação que se opõem ao governo federal. Viabiliza-se, assim, um processo de construção do currículo que se desenvolve a partir de princípios balizadores comuns e das especificidades e dos interesses da escola e de sua comunidade. Ainda que os procedimentos de avaliação, os livros didáticos, os programas de formação continuada de docentes e os recursos tecnológicos empregados na difusão das iniciativas do governo federal dificultem o sucesso das propostas centradas na escola, os resultados das disputas não são totalmente previsíveis. Abrem-se, portanto, espaços para a visão de currículo que o concebe como instrumento de comunicação entre teoria e prática, como expressão da função socializadora e cultural da escola, como campo de desenvolvimento de alunos e docentes, como campo de conflitos e de alianças que se expressam em decisões coletivamente tomadas.

\section{Considerações finais}

A despeito de suas limitações, a revisão de reformas curriculares das décadas de 1980 e 1990 estimula algumas reflexões, abordadas a seguir.

Focalizo, em primeiro lugar, aspectos referentes ao caráter claramente político das reformas examinadas. Estudo de Bomeny e Feital (1998) sugere que uma proposta fortemente marcada por uma dada orientação política torna-se alvo fácil de outros partidos que se elejam, finda a administração que a adota. A meu ver, a coloração político-partidária das reformas é inevitável, por refletir o compromisso e o posicionamento de um governo escolhido por uma população. No caso de governos que se opõem às políticas e às ideologias dominantes, a coloração certamente se intensifica, ao se evidenciar o esforço por atenuar as dificuldades sofridas pelas camadas mais desfavorecidas da população, dentre as quais se inclui a vivência de uma escola ainda pouco democrática e ainda excludente. Cabe, entretanto, um alerta no sentido de que o uso político de uma reforma se dê de modo particularmente ético, referendando o comprometimento com uma escola de qualidade e expressando todo o cuidado necessariamente devido ao fenômeno educativo, de profundos efeitos na vida e na identidade de considerável número de crianças e adolescentes. 
A política ziguezague (Cunha 1995), que corresponde às oscilações e mudanças na política educacional em função da entrada de novos administradores e que contribui significativamente para o insucesso das reformas e para a descrença do professorado em relação a elas, pode ser amenizada quando a reforma se elabora com efetivos envolvimento e participação dos sujeitos mais diretamente interessados. Sugiro ser o currículo centrado na escola, e não o decidido nos órgãos administrativos centrais, o que mais favorece o comprometimento de professores e alunos. Devidamente engajados, serão eles os mais leais guardiães das iniciativas que ajudaram a conceber e a implantar. Tentativas de derrubá-las serão, então, rechaçadas. Aliás, a própria comunidade, habituada a uma escola que funciona bem, ajudará a cerrar fileiras em sua defesa. Cabe, então, promover estratégias que estimulem e preservem uma ampla participação nas diferentes etapas do processo. Essa participação, bastante incentivada nas reformas examinadas, se não é suficiente para modificar substantivamente os índices de evasão e repetência de nossos sistemas escolares, pode, além de facilitar a adesão de alunos, professores e pais às reformas, criar um clima mais democrático nas secretarias, nas escolas e nas salas de aula. Ainda que uma reforma curricular não seja o principal motor de justiça social, tornar a escola "um ambiente mais democrático e igualitário é um objetivo tão legítimo quanto o de usá-la como instrumento de transformação da sociedade" (Silva 1990, p. 64).

A defesa do currículo centrado na escola apóia-se também no pressuposto de que não faz sentido a tentativa de se definir um currículo crítico universalmente válido.

É na intersecção da teoria com as práticas educacionais existentes, historicamente localizadas, que se podem plantar as bases do desenvolvimento dos vários currículos críticos e progressistas ou das várias pedagogias críticas. (Idem, op. cit., p. 64)

Todavia, centrar o currículo na concretude das realidades escolares não pode significar omissão da secretaria ou sua retirada do cenário. Pelo contrário, além dos indispensáveis recursos e incentivos a serem propiciados em uma interação constante com a escola, discussões entre os sujeitos dessa escola e técnicos comprometidos e abertos ao diálogo são necessárias para incrementar a qualidade do trabalho e garantir o sucesso da proposta, que é sempre uma intenção, um projeto, que adquire 
forma própria em cada escola e em cada sala de aula. É essencial, portanto, que a secretaria procure acompanhar, entender e mesmo orientar como se materializa a proposta em questão nas escolas. A partir da discussão e da crítica das práticas e das atividades que se desenvolvem é que se podem tomar as decisões referentes a como melhor implementar, questionar e/ou transformar a proposta. Ou seja, a proposta é um caminho (Kramer 1999), em cuja construção devem se envolver todos os sujeitos interessados no processo.

Outro aspecto que pode contribuir para a estabilidade e a permanência de iniciativas pedagógicas é a organização da própria Secretaria de Educação. A meu ver, quanto mais estruturados política e administrativamente estiverem a Secretaria e o próprio governo estadual ou municipal, mais fácil e mais provável será a preservação e a renovação de experiências bem-sucedidas (Bomeny e Feital 1998). O mesmo pode ser dito em relação à formulação e à implantação de novas propostas. Ainda que controles e regulamentações estatais constituam evidentes limites para novos arranjos e dificultem a reordenação de especificações há muito cristalizadas, uma máquina bem estabelecida e bem "azeitada" pode reduzir os entraves burocráticos que usualmente restringem novas organizações do tempo, do espaço e do conhecimento na escola, favorecendo, então, mudanças menos superficiais.

Em segundo lugar, focalizo a reorganização do conhecimento escolar que as recentes reformas buscam promover. Em todas elas, as disciplinas legalmente definidas são preservadas. Delas procura-se selecionar, de forma crítica, o conhecimento acumulado historicamente que, em confronto com os saberes trazidos pelos estudantes, pode propiciar a produção de novos conhecimentos e permitir a análise dos problemas colocados pela atualidade. Contudo, como já acentuei, mesmo que a interdisciplinaridade possa significar um avanço em relação à disciplinaridade pura e simples, as disciplinas continuam presentes no trabalho efetuado. Como elas não dão conta de muitos problemas que hoje afetam nosso cotidiano, seriam necessários saberes que se situassem além dos disciplinares, seriam necessários saberes híbridos para pensar problemas híbridos (Gallo 1999; Alves e Garcia 1999).

Por outro lado, além das exigências legais, há de se ressaltar a sensível dificuldade de se implantar em um sistema escolar uma proposta que de fato configure um rompimento com as limitações disciplinares. A 
familiaridade dos professores com as disciplinas, adquirida na prática que desenvolvem, nos livros didáticos com que trabalham - também eles organizados segundo as disciplinas -, bem como na formação recebida nos cursos freqüentados, acaba por promover a internalização dos princípios da disciplinaridade e por criar um habitus difícil de ser superado. Nesse contexto, experiências de ensino por eixos, temas ou projetos raramente promovem algo além de rupturas eventuais e passageiras. Experiências em que se transcendam os saberes disciplinares são, então, ainda menos passíveis de aceitação e de sucesso.

Além disso, não há como negar que a organização disciplinar pode ser mesmo benéfica em determinados estágios da vida escolar, tendo-se em vista que promove economia de tempo na aprendizagem, bem como facilita a sistematização de conceitos, idéias e princípios, garantindo, por conseguinte, melhores assimilação e retenção de um material que precisa ser aprendido. Desse modo, estruturas curriculares que fogem da lógica disciplinar acabam sendo mais comuns nos primeiros anos da escola fundamental, quando a sistematização ainda se faz menos necessária, e no ensino superior, quando as especializações certamente acarretam a transgressão das fronteiras disciplinares. Mesmo assim, neste último caso, há de se levar em conta as diferenças entre cursos que correspondem a ciências "puras", como Física ou Matemática, e cursos que correspondem, dominantemente, a aplicações de diferentes áreas de conhecimento, como Educação, Arquitetura ou Enfermagem. Pode-se argumentar que o trabalho pautado na interdisciplinaridade ou na transversalidade, desenvolvido por meio de problemas, temas ou projetos, se revela mais viável e conveniente nos campos aplicados que nos conhecimentos mais "puros", mais fortemente centrados na lógica das disciplinas e, conseqüentemente, mais usual e facilmente ensinados e aprendidos nas salas de aula em conformidade com os parâmetros tradicionais de organização.

Pode-se, todavia, sugerir que se coloque como horizonte a produtividade de uma permanente tensão entre as disciplinas, explorando-se ao máximo as possibilidades de trocas de experiências e vivências dos atores que as constroem. Trata-se, em síntese, de manter aberto o diálogo entre os diferentes, de propiciar a prática de aproximação entre as disciplinas, ainda que não se pretenda nem submetê-las a qualquer coordenação nem fundi-las com vistas a recuperar a unidade perdida pelo fracionamento que a ciência moderna trouxe ao conhecimento e ao próprio mundo (Veiga-Neto 1994, 1997). 
Em terceiro lugar, focalizo a relação entre o pensamento sobre o currículo e as reformas curriculares. Pode-se dizer que as teorias do currículo influenciam as reformas? Quais as mais influentes? Que teorias norteiam as teorias que enfatizam flexibilização e integração curricular?

Afirmo, inicialmente, que a presença de teorizações que enfocam questões de currículo é visível nas reformas examinadas. Verifico, também, serem as teorias críticas mais centradas nos problemas da educação brasileira, ou seja, a pedagogia dos conteúdos e a educação popular, as que mais parecem ter ocupado espaços e fundamentado iniciativas de reorientação curricular. Verifico, ainda, serem os princípios de Paulo Freire os que dominantemente orientam as propostas curriculares que enfatizam a integração curricular.

Apesar de suas visíveis diferenças, as duas tendências compartiIham um claro comprometimento político e o foco na especificidade de nossa situação. $O$ fracasso da criança das camadas populares na escola, bem como a necessidade de inseri-las nas diferentes esferas da vida social, constituem propósitos comuns, apesar dos distintos trajetos escolhidos para o alcance dessas metas. Para os dois grupos, os direitos das populações oprimidas à democracia e à cidadania representam bandeiras a serem perseguidas com base nas propostas curriculares adotadas e nas tentativas de gestão democrática implantadas nas escolas.

A preocupação com a realidade brasileira, evidente tanto na pedagogia dos conteúdos como na educação popular, conduz à discussão referente a teorias mais ou menos autóctones, a incorporações mais ou menos críticas de modelos estrangeiros. Estudo por mim realizado (Moreira 1990) procura compreender o processo de transferência educacional à luz da emergência do campo do currículo no Brasil, sob forte influência norteamericana. Rejeitando a idéia de cópia, bem como a possibilidade de teorias elaboradas no Brasil sem a "contaminação" do discurso estrangeiro, indico a possibilidade de transferências expressarem a intenção de conferir ao material transferido a cor local necessária ao emprego no contexto que o recebe, bem como o propósito de criticar o material, entender o processo de sua construção e os interesses incorporados, de modo a efetuar os ajustes e as mudanças indispensáveis para eliminar aspectos opressivos.

Atualmente, o fenômeno da influência estrangeira na produção cultural de um país de Terceiro Mundo é ainda mais complexo em decorrência 
do movimento de globalização cultural que se incrementou nas últimas décadas, propiciando a convivência de fatores contraditórios. O fluxo de informações e conhecimentos que contribuem para essa globalização tanto pode causar homogeneização, invasão e destruição de processos culturais, como estimular uma apropriação crítica de idéias e teorias elaboradas pelo "outro" (Moreira e Macedo 1999).

Toda essa interação impede que se aceite hoje a idéia de uma cultura em estado puro, isenta de outras manifestações. Nesse mesmo sentido, não cabe mais considerar que as diferentes culturas se encontram dispostas na sociedade, como se supunha, em distintos patamares (García Canclini 1990). As comunicações entre culturas são crescentes e freqüentes, constituindo um processo de hibridização no qual elementos de diversas origens e diferentemente hierarquizados se encontram, se atritam, se repelem, se misturam e promovem sínteses por vezes criativas.

Mas o processo de hibridização não ocorre necessariamente de modo democrático. A desigualdade no acesso aos bens materiais e simbólicos persiste, tornando os setores populares e os países do Terceiro Mundo menos influentes na escolha dos materiais a serem hibridizados (Sarlo 1999). Conseqüentemente, a hibridização nem sempre resulta favorável aos pleitos de tais grupos e países, a despeito de envolver também subversão, translação e desarticulação de materiais produzidos em espaços mais poderosos.

Nessa perspectiva, cabe examinar de que modo o hibridismo expresso na teoria do currículo, em que distintas tradições e movimentos se combinam, construindo coalizões que originam consensos (Dussel, Tiramonti e Birgin 1998), pode se desdobrar a partir de contribuições mais livre e democraticamente escolhidas. O que se propõe, então, é que as leituras de teorias formuladas no Primeiro Mundo desafiem, desestabilizem e transformem normas, valores e interesses subjacentes a essas teorias, levando-as a "funcionar a nosso favor". O que se propõe é que os especialistas em currículo tanto dirijam seus olhares para a realidade concreta da escola brasileira como dialoguem criticamente com o discurso do Primeiro Mundo.

Por fim, importa destacar o fato de se encontrarem nas duas tendências em pauta princípios e proposições capazes de nortear tanto a formulação de currículos como a prática pedagógica. Chega-se, assim, à questão da necessidade de confluência entre a teoria do currículo e 
as práticas escolares. Pode-se esperar que a teoria não siga caminhos distanciados dos lugares de decisões sobre currículo? Quem faz e como se faz a mediação entre teorias complexas e abstratas e a realidade da escola e da sala de aula? Como fazer para que as teorias cheguem de fato às salas de aula?

O afastamento da teoria crítica do currículo em relação à prática tem sido discutido no Brasil e no Primeiro Mundo e interpretado mesmo como uma das causas da propalada crise dessa teorização. Com base em Gore (1993), argumento, em outro estudo, que teorizar sobre a prática escolar não precisa configurar prescrição, podendo constituir uma abordagem contextualizada e incluir aspectos propositivos que favoreçam ao professorado o melhor delineamento de sua ação pedagógica. Insisto, então, na defesa da centralidade da prática nos estudos de currículo, acrescentando que o foco na prática não deve ser compreendido como secundarização da teoria. Sua importância é para mim evidente. No entanto, concordo com Lefebvre (1979) quando afirma que "a coerência abstrata, a demonstração teórica desligada da atividade social e da verificação prática não têm nenhum valor" (p. 27).

Sugiro, também, que os especialistas em currículo reforcem o diálogo com os que tomam decisões em diferentes níveis, participando na elaboração, acompanhamento e avaliação de propostas curriculares oficiais. Como se constatou nos casos estudados, a presença de pesquisadores nos esforços de mudança curricular pode abrir espaços para a revitalização tanto da teoria como da prática. Destaco, ainda, a importância do diálogo entre os que refletem e teorizam sobre currículo e os que centram suas atenções nos aspectos teóricos e práticos das disciplinas específicas. Segundo Silva (1990), trata-se de dois mundos separados e incomunicáveis. Desse divórcio resultam sensíveis dificuldades na transposição de princípios mais gerais para o âmbito mais especializado de cada disciplina. Assim, um diálogo intenso entre curriculistas e especialistas nas disciplinas certamente beneficiaria a todos e possibilitaria formas mais criativas de efetivar renovações curriculares.

Como reformar currículos é alterar a prática da educação, está-se diante de problema de relação entre teoria e prática que interessa e concerne a muitos, não apenas aos técnicos, aos especialistas e aos professores. Cabe, então, tanto promover o diálogo entre esses grupos, como estendê-lo para além das escolas, das universidades e dos sistemas escolares. 
Nesse sentido, continuam válidas as palavras de Silva (1990), em seu estudo sobre as lições e as dúvidas de duas décadas de teorização curricular crítica.

\begin{abstract}
Temos ainda que descobrir como romper o isolamento da esfera teórica e acadêmica, se quisermos que nossas teorias e elaborações sobre educação e currículo não se limitem a descrever círculos em torno de si mesmas, num movimento de auto-satisfação. Essa integração deveria envolver uma cooperação mais estreita entre pesquisadores e professores universitários, professores de primeiro e segundo graus, e organizações populares tais como sindicatos e associações de moradores. (p. 66)
\end{abstract}

Somente praticando essa integração aprenderemos a desenvolvêla, a ampliar suas possibilidades e a romper seus limites.

\title{
Notas
}

1. Neidson Rodrigues é professor da UFMG, tendo concluído seu doutorado na PUC-São Paulo sob a orientação de Dermeval Saviani.

Governaram o estado de Minas Gerais, no período da reforma, Tancredo Neves (depois candidato à Presidência da República) e Hélio Garcia, ambos do PMDB, partido de oposição aos militares.

2. Professora universitária e pesquisadora, fundadora e primeira presidente da Associação Nacional de Educação. Autora de livro bastante influente na década 1980, Magistério de primeiro grau: da competência técnica ao compromisso político, originalmente sua tese de doutorado, defendida na PUC-São Paulo sob orientação de Dermeval Saviani. Na década de 1990, Guiomar Namo de Mello reformula suas posições, vindo a trabalhar no Banco Mundial, em Washington. Hoje é membro do Conselho Nacional de Educação, indicada pelo Presidente Fernando Henrique Cardoso.

O prefeito de São Paulo na ocasião da reforma era Mário Covas, então filiado ao PMDB.

3. O governador do estado do Rio de Janeiro no período em pauta era Leonel Brizola, presidente do Partido Democrático Trabalhista (PDT), de cunho populista e de oposição aos militares. Em sua volta ao Brasil, em 1979, após o período de exílio, Brizola buscou marcar sua condição de herdeiro do trabalhismo de Vargas e Goulart, reorganizando o PTB, fechado pela ditadura militar. Após batalha judicial, perdeu a sigla para Ivete Vargas. Brizola criou, então, o PDT.

Ainda que não fosse secretário de Educação, mas sim vice-governador e secretário de Cultura, foi Darcy Ribeiro quem liderou a concepção e a implementação de escolas de tempo integral (CIEPs) em todo o estado.

4. Os prefeitos de São Paulo, Porto Alegre e Belo Horizonte filiavam-se ao PT. O do Rio de Janeiro, inicialmente filiado ao PDT, mudou para o PFL e posteriormente para o PTB. 
5. Foram secretários de Educação no período da reforma os professores Paulo Freire e Mário Sérgio Cortella, ambos da Pontifícia Universidade Católica de São Paulo. Cortella defendeu sua tese de doutorado sob orientação de Freire. À frente da Diretoria de Orientação Técnica, encontrava-se Ana Maria Saul, professora da mesma universidade e especialista em currículo.

Luiza Erundina (na época PT, hoje PSB) era a prefeita de São Paulo na ocasião. Como o PT não conseguiu eleger o novo prefeito, a proposta foi abandonada na gestão seguinte.

6. O projeto Escola Cidadã inicia-se em 1994, na segunda gestão da administração PT em Porto Alegre, quando Tarso Genro era prefeito e Sonia Pilla Vares, a secretária de Educação. A partir de 1997, assumiu a prefeitura Raul Pont, nomeando José Clóvis de Azevedo como secretário de Educação. Praticamente a mesma equipe tem permanecido à frente da condução do processo de reorientação curricular.

7. Os sete seminários internacionais já realizados originaram livros contendo os trabalhos apresentados. Boa parte dos textos referentes aos demais eventos está registrada em revistas e cadernos publicados pela Secretaria. Em todas as publicações é dominante a preocupação com o currículo. Segundo recente investigação (Frigotto 1999), o que distingue as temáticas dos livros e as temáticas dos cadernos e das revistas é o caráter mais amplo dos primeiros e o mais restrito dos segundos. Nos livros, encontram-se textos de autores estrangeiros, muitos associados aos estudos culturais e ao pensamento pós-moderno e pós-estrutural, muitos associados à teorização crítica de currículo, nos quais se discutem os temas mais contemporâneos do discurso sobre currículo internacional. O VII Seminário representou uma ruptura, na medida em que Tomaz Tadeu da Silva e Luiz Heron da Silva deixaram de participar da organização e que novos organizadores (José Clóvis de Azevedo, secretário de Educação de Porto Alegre, Pablo Gentili, Andréa Krug e Cátia Simon) passaram a privilegiar questões políticas e pedagógicas em vez de autores e temas pós-modernos, bastante presentes nos seminários anteriores. Afirmou-se, nessa ocasião, que os seminários internacionais constituíam espaços culturais abertos à crítica, à deliberação e à construção comum de saberes, espaços esses nos quais "podemos contribuir para conquistar nosso direito de imaginar, de sonhar e de desejar uma sociedade sem exclusões" (Azevedo, Gentili, Krug e Simon 2000, p. 10).

Os cadernos e as revistas tendem a focalizar mais de perto o cotidiano da prática curricular, o currículo em ação nas escolas e nas salas de aula, divulgando mais as preocupações de autores associados ao discurso pedagógico crítico. Desse modo, o caráter mais abstrato e mais complexo da teoria do currículo contemporânea, difundida nos seminários internacionais até 1999, parece ser compensado pelo tom mais pedagógico dos outros eventos, nos quais o foco dominante é a interdisciplinaridade. O VIII Seminário Nacional "Escola Cidadã: A educação popular faz história", por exemplo, realizado em abril de 2000, propôs-se a socializar a reflexão de práticas pedagógicas que vêm sendo gestadas cotidianamente e que se pautam pelo comprometimento com uma política educacional inclusiva.

Pode-se dizer que até 1999 os dois tipos de seminários distinguiam-se pelas abordagens teóricas que buscavam discutir e difundir. $O$ que parecia uni-las eram posicionamentos políticos comuns: a valorização da escola; o compromisso com a democratização da sociedade e com a socialização do conhecimento; a defesa da participação da comunidade nas decisões; a rejeição aos princípios pedagógicos pautados em preceitos neoliberais; o respeito ao universo cultural do aluno; a quebra de barreiras entre a cultura erudita e a cultura popular. A partir de 2000 , as abordagens se aproximam, configurando-se uma clara opção pelo enfoque crítico na análise de questões educacionais e pedagógicas. 
8. Tendo obtido expressiva votação no primeiro turno, Tarso Genro, segundo a primeira rodada de pesquisa Datafolha após o primeiro turno, possui $55 \%$ das intenções de voto (Folha de $S$. Paulo, 8 de outubro de 2000).

9. Patrus Ananias (PT) foi o prefeito de Belo Horizonte e Glaura Vasques de Miranda, professora da Universidade Federal de Minas Gerais, a secretária de Educação. A proposta da Escola Plural foi liderada por Miguel Arroyo, secretário municipal adjunto de Educação, também professor da Universidade Federal de Minas Gerais. Embora a coligação PT-PSB tenha sido vencedora na eleição de 1996, mudanças na administração da Secretaria de Educação têm afastado a Escola Plural de sua concepção inicial.

10. O Rio de Janeiro talvez tenha sido o único caso em que uma reformulação curricular tida como inovadora foi realizada em estado não governado por partido de oposição ao governo federal. A concepção e a implementação inicial da proposta foram lideradas por Regina Assis, professora da Universidade do Estado do Rio de Janeiro e da Pontifícia Universidade Católica do Rio de Janeiro. César Maia (hoje do PTB) era o prefeito da cidade. A eleição de Luiz Paulo Conde, membro do secretariado de Maia, para o mandato seguinte, garantiu a continuidade da proposta. Nas eleições de 2000, Luiz Paulo Conde (PFL) e César Maia (PTB) disputam o segundo turno. Assim, qualquer que seja o eleito, há probabilidade de que o Projeto Multieducação continue a ser desenvolvido.

\section{Recebido para publicação em Setembro de 2000.}

\section{Alternative proposals for curricula: Limits and progress}

ABSTRACT: This article focuses on curriculum reforms that took place in some states and municipalities in Brazil in the 1980s and the 1990s. These reforms can be characterized by their intent to fashioning a more critical and democratic school. In other words, they were in opposition to the hegemonic official discourse. The article attempts to characterize such curriculum reforms and stress their achievements. It argues that alternatives are possible, even desirable, and that they deserve to be publicized and studied.

Key words: Curriculum proposal, alternatives, democratization, curricular integration, school-centered curriculum

\section{Bibliografia}

ALVES, N. e GARCIA, R.L. "Atravessando fronteiras e descobrindo (mais uma vez) a complexidade do mundo. In: ALVES, N. e GARCIA, R.L. (orgs.), O sentido da escola. Rio de Janeiro: DP\&A, 1999, pp. 81-110. 
APPLE, M.W. Official knowledge: Democratic education in a conservative age. Nova lorque: Routledge, 1993.

- "A política do conhecimento oficial: faz sentido a idéia de um currículo nacional?". In: MOREIRA, A.F.B. e SILVA, T.T. (orgs.), Currículo, cultura e sociedade. São Paulo: Cortez, 1994.

. e BEANE, J. (orgs.). Escolas democráticas. Porto: Porto Editora, 2000.

ARELARO, L. "A ousadia de fazer acontecer o direito à educação. Algumas reflexões sobre a experiência de gestão nas cidades de São Paulo (1989/92) e Diadema (1993/96)". In: OLIVEIRA, D.A. e DUARTE, M.R.T. (orgs.), Política e trabalho na escola: administração dos sistemas públicos de educação básica. Belo Horizonte: Autêntica, 1999, pp. 191-207.

AZEVEDO, J.C. "Escola cidadã: a experiência de Porto Alegre". In: OLIVEIRA, D.A. e DUARTE, M.R.T. (orgs.), Política e trabalho na escola: administração dos sistemas públicos de educação básica. Belo Horizonte: Autêntica, 1999.

. GENTILI, P.; KRUG, A. e SIMON, C. "Apresentação". In: AZEVEDO, J.C.; GENTILI, P.; KRUG, A. e SIMON, C. (orgs.), Utopia e democracia na educação cidadã. Porto Alegre: Ed. da Universidade/UFRS/ Secretaria Municipal de Educação, 2000, pp. 9-10.

BARRETO, E.S.S. Propostas curriculares oficiais. São Paulo: Fundação Carlos Chagas, 1995.

. "Tendências recentes do currículo no ensino fundamental no Brasil". In: BARRETO, E.S.S. (org.), Os currículos do ensino fundamental para as escolas brasileiras. Campinas: Autores Associados; São Paulo: Fundação Carlos Chagas, 1998.

BELO HORIZONTE, SECRETARIA MUNICIPAL DE EDUCAÇÃO, Escola Plural, 1994.

BOMENY, H.M.B. e FEITAL, R. "Descentralização no Brasil: reforma educativa em curso". In: BOMENY, H.M.B. (org.), Ensino básico na América Latina: experiências, reformas, caminhos. Rio de Janeiro: Ed. UERJ, 1998, pp. 39-58.

BURBULES, N. "Reform as the social administratrion of the child: globalization of knowledge and power". Trabalho apresentado no Congresso de Educação Comparada, Cidade do Cabo, África do Sul, 1998. 
CARLGREN, I. "Currículum nacional como compromiso social o política discursiva? Reflexiones sobre el proceso de configuración del currículum". Revista de Estudios del Currículum, Barcelona, vol. 1, n. 2, pp. 77-104, 1998.

CUNHA, L.A. Educação, Estado e democracia no Brasil. São Paulo: Cortez; Niterói: EDUFF; Brasília: FLACSO do Brasil, 1991.

. “Os males do ziguezague”. Presença Pedagógica, n. 6, 1995, pp. 5-15.

DUSSEL, I.; TIRAMONTI, G. e BIRGIN, A. "Hacia uma nueva cartografía de la reforma curricular: reflexiones a partir de la descentralización argentina". Revista de Estudios del Currículum, Barcelona, vol. 1, n. 2, 1998, pp. 132-161.

FREIRE, P. e SHOR, I. A pedagogy for liberation: dialogues on transforming education. Londres: MacMillan, 1987.

FRIGOTTO, E. Construção curricular e demarcação discursiva: gênese e afirmação da proposta da Escola Cidadã de Porto Alegre. Tese de doutorado. Departamento de Educação, Pontifícia Universidade Católica do Rio de Janeiro, 1999.

GALLO, S. "Transversalidade e educação: pensando uma educação nãodisciplinar". In: ALVES, N. e GARCIA, R.L. (orgs.), O sentido da escola. Rio de Janeiro: DP\&A, 1999, pp. 17-41.

GARCÍA CANCLINI, N. Culturas híbridas: estratégias para entrar y salir de la modernidad. México: Grijalbo, 1990.

GIROUX, H.A. "Pedagogia do conteúdo versus pedagogia da experiência: esta é uma má polarização". Entrevista dada a Tomaz Tadeu da Silva. Educação \& Realidade, vol. 11, n. 1, 1986, pp. 59-67.

GOODSON, I. Studying curriculum. Buckingham: Open University Press, 1994.

GORE, J.M. The struggle for pedagogies: critical and feminist discourses as regimes of truth. Nova lorque: Routledge, 1993.

GORODICHT, C. e SOUZA, M.C. "Complexo temático". In: Silva, L.H. (org.), Escola cidadã: teoria e prática. Petrópolis: Vozes, 1999, pp. 76-84.

KRAMER, S. "Propostas pedagógicas ou curriculares: subsídios para uma leitura crítica". In: MOREIRA, A.F.B. (org.), Currículo: políticas e práticas. Campinas: Papirus, 1999, pp. 165-183. 
LEFEBVRE, H. Sociologia de Marx. Rio de Janeiro: Forense Universitária, 1979.

LIBÂNEO, J.C. Fundamentos teóricos e práticos do trabalho docente: estudo introdutório sobre Pedagogia e Didática. Tese de doutorado. Pontifícia Universidade Católica de São Paulo, 1990.

MELLO, G.N. Educação escolar: paixão, pensamento e prática. São Paulo: Cortez; Campinas: Autores Associados, 1986.

MOREIRA, A.F.B. Currículos e programas no Brasil. Campinas: Papirus, 1999. . "A crise da teoria curricular crítica". In: Costa, M.V. (org.), O currículo nos limiares do contemporâneo. Rio de Janeiro: DP\&A, 1998, pp. 11-36.

. "Neoliberalismo, currículo nacional e avaliação". In: SILVA, L.H. e AZEVEDO, J.C. (orgs.), Reestruturação curricular: teoria e prática no cotidiano da escola. Petrópolis: Vozes, 1995, pp. 94-107.

. e MACEDO, E.F. "Faz sentido ainda hoje o conceito de transferência educacional?" In: Moreira, A.F.B. (org.), Currículo: políticas e práticas. Campinas: Papirus, 1999, pp. 11-28.

POPKEWITZ, T.S.; PITMAN, A. e BARRY, A. "El milenarismo en la reforma educativa de los años ochenta". Revista de Estudios del Currículum, vol. 1, n. 2, 1998, pp. 7-33.

RIO DE JANEIRO, SECRETARIA MUNICIPAL DE EDUCAÇÃO DO RIO DE JANEIRO. Multieducação: núcleo curricular básico, 1996.

SÃO PAULO, SECRETARIA MUNICIPAL DE EDUCAÇÃO DE SÃO PAULO. O movimento de reorientação curricular na Secretaria Municipal de Educação de São Paulo. Documento 1, 1989a.

SÃO PAULO, SECRETARIA MUNICIPAL DE EDUCAÇÃO DE SÃO PAULO. O movimento de reorientação curricular na Secretaria Municipal de Educação de São Paulo. Documento 2, 1989b.

SÃO PAULO, SECRETARIA MUNICIPAL DE EDUCAÇÃO DE SÃO PAULO. Um primeiro olhar sobre o projeto, 1990a.

SÃO PAULO, SECRETARIA MUNICIPAL DE EDUCAÇÃO DE SÃO PAULO. Estudo preliminar da realidade local: resgatando o cotidiano, 1990b.

SÃO PAULO, SECRETARIA MUNICIPAL DE EDUCAÇÃO DE SÃO PAULO. Tema gerador e a construção do programa: uma nova relação entre currículo e realidade, 1991. 
SARLO, B. Escenas de la vida posmoderna: intelectuales, arte y videocultura en la Argentina. Buenos Aires: Ariel, 1999.

SAVIANI, D. "Competência técnica e compromisso político ou (O pomo da discórdia e o fruto proibido)". Educação \& Sociedade, n. 15, 1983, pp. 111-143.

SILVA, T.T. "Currículo, conhecimento e democracia: as lições e as dúvidas de duas décadas". Cadernos de Pesquisa, n. 73, 1990, pp. 59-66.

SOUZA, R.F. "A produção intelectual sobre currículo a partir dos anos 80 ". Em Aberto, n. 58, 1983, pp. 117-128.

TEIXEIRA, L.H.G. "Políticas públicas de educação e mudança nas escolas: um estudo da cultura escolar". In: OLIVEIRA, D.A. e DUARTE, M.R.T. (orgs.), Política e trabalho na escola: administração dos sistemas públicos de educação básica. Belo Horizonte: Autêntica, 1999, pp. 177-190.

SOUZA SANTOS, B. A crítica da razão indolente: contra o desperdício da experiência. São Paulo: Cortez, 2000.

VEIGA-NETO, A. "Currículo e interdisciplinaridade". In: MOREIRA, A.F.B. (org.), Currículo: questões atuais. Campinas: Papirus, 1997, pp. 59-102.

WHITTY, G.; POWER, S. e HALPIN, D. Devolution \& choice in education: the school, the state and the market. Buckingham: Open University Press, 1998.

ZACCUR, E. e GARCIA, R.L. "Uma experiência de rompimento com a divisão disciplinar". Trabalho apresentado na XIX Reunião Anual da ANPEd, Caxambu, 1996. 